\title{
Essay \\ The Challenging Shift to a Circular Economy: The Relevance of Social Ecology in Effective Transition
}

\author{
Saleem H. Ali \\ Chair in Sustainable Resource Development, University of Queensland, St Lucia QLD 4072, Australia; \\ saleem@alum.mit.edu
}

\begin{abstract}
The concept of a "circular economy" needs a more cogent theoretical anchor which will allow for transference of its goals and methods of attainment across cases. Tensions between ecological goals of this concept and the social implications of its implementation need to be addressed. This paper attempts to provide a theoretical framework for harnessing the strengths of a circular economy. Building on theories of social ecology which are predicated in Murray Bookchin's notion of "dialectical naturalism", the analysis presented here addresses some of the criticism of circular economic paradigms, such as their potential for stifling innovation or a neglect of human development challenges. A model for managing human "need" and "greed" within a circular economy framework is presented that also incorporates consumer choice and innovation. Planned obsolescence as a means of livelihood generation is also problematized with a view towards balancing durability of products on the one hand and ensuring throughput for manufacturing employment and innovation incentives on the other. Finally, the need for governance systems is considered to ensure that a planetary vision for a circular economy can be realized that efficiently harnesses local initiatives rather than an atomized and insular view of circularity.
\end{abstract}

Keywords: circular economy; social ecology; consumerism; dialectical naturalism; mining

\section{INTRODUCTION}

The concept of a circular economy posits a definitive paradigm shift in the way industrial processes relate to the modern economy. The convention economic model has been focused on linear material flows from mines to markets. However, a circular economy approach that has emerged in recent years suggests the need to reconfigure the economic systems around materials recycling and hence circularity (World Economic Forum, 2014). As with any such major shift in human endeavour, a strong philosophical underpinning can help to draw theoretical insights which in turn allow for transferability of concepts across cases. In this article, my aim is to suggest that a form of dialectical analysis has particular potential in addressing many of the concerns raised by critics of a circular economy. Circularity in modern discourse often implies stasis and thus the circular economy paradigm encounters the same criticism from many neoclassical economists which was faced by Herman Daly three decades ago with his concept of a "Steady-State Economy." There were two key avenues of critique with regard to such an approach: a) "steady state" implied an atrophy of incentives for innovation and hence would diminish the potential for technological advancement of humanity; b) the development needs of the indigent on the planet meant we had a moral imperative for economic growth that would be precluded by a steady state economy. It is important to note, however, that proponents of circular economy are willing to embrace growth, so long as material flows are better cycled within the growth paradigm - they are thus focused on stability at the microeconomic level rather than having a steady-state at the macro-economic level.

In this conceptual paper, I provide a way by which we can respond to these two key critiques by revisiting the theory of social ecology and adapting it for a circular economic system. 


\section{The Relevance of Social Ecology Theory}

The term "Social Ecology" has developed in two parallel intellectual traditions which have seldom communicated with each other despite having congruent objectives. First, the concept of social ecology was developed in psychological discourse, particularly by Arnold Binder (1972), and found grounding at the University of California through the establishment of the "School of Social Ecology." The core aspects of this approach were subsequently summarized in six principles by Dave Taylor ${ }^{1}$ as follows:

1) Identify a phenomenon as a social problem;

2) View the problem from multiple levels and methods of analysis;

3) Utilize and apply diverse theoretical perspectives;

4) Recognize human-environment interactions as dynamic and active processes;

5) Consider the social, historical, cultural and institutional contexts of people-environment relations;

6) Understand people's lives in an everyday sense.

The field in this inception builds upon traditions of "human ecology" which were developed in geography, anthropology and environmental history. The context being that humans were an essential part of ecological systems and that environmental problem-solving must consider the transformative role of human societies on the environment.

Second, the term was embraced by the "Green Anarchist" scholar Murray Bookchin as a response to what he perceived as a hierarchical approach to ecological problem-solving that was being presented in policy-making circles. Instead of regulating our way to solutions, Bookchin and his protégés at the Institute for Social Ecology (based in Plainfield, Vermont USA), were focused on social transformation thorough decentralized inculcation of ecological ethics. It is important to note that through his intellectual development of social ecology, Bookchin dismissed some of the absolutist elements of anarchist thought around electoral participation. Instead, "green anarchy" focused on how grassroots community organizations which had direct connections to the land and livelihoods could contribute effectively in local governance.

Despite his atheism, there was perhaps an inadvertent element of the Catholic social teaching of "subsidiarity" within the approach posited by Bookchin, as his writings matured whereby the lowest functional level of governance was to be given ascendancy. Generating circular economies at a micro-scale through intentional communities such as Eco-villages bear the hallmark of such subsidiarity approaches. Some of the criticism of European Union (EU) policies on a circular economy also emanate from such a detachment from broader planetary policies and linkages, given that the Maastrict treaty which enshrined EU policy mandates was also premised on the principle of subsidiarity (Gregson et al., 2015). Interestingly enough, the most recent encyclical on ecology issued by Pope Francis, entitled Laudato si' (translated from Medieval Italian as "Praise be to You" with subtitle: "On Care For Our Common Home") echoes these themes of subsidiarity. At the 2015 conference of the Transnational Institute for Social Ecology, Ian Bekker (2015) astutely observed an "overlap between the message of Laudato si' and the Social Ecology project of Murray Bookchin."

However, there is a clear tension which needs to be acknowledged between the localized push of subsidiarity for sustainable systems versus the pull of globalization as a means of recognizing connections between planetary processes. A conventional reading of social ecology could lead us to ostensibly sustainable communes, meeting their metrics of circularity in terms of waste reuse and regeneration, but with possibly inefficient outcomes or hidden and essential linkages to the global supply chains. The much-quoted aphorism "think globally, act locally" becomes a futile guide in most contexts because "thought" and "action" remain intrinsically connected at multiple scales. For example to make some communities most effectively self-reliant on energy with wind turbines or solar panels, we still need to harness minerals like terbium or neodymium which link us to

\footnotetext{
${ }^{1}$ Presented in David Taylor's doctorate at UCI: Begging for Change: A Social Ecological Study of Aggressive Panhandling and Social Control in Los Angeles, 1999.
} 
global supply chains. Those linkages are essential for aggregate metrics of sustainability at a planetary level which need just as much attention as the viability of human communities at a local level.

Most consequential to our discussion of how to better theorize circular economic approaches for broader applicability we need to revisit another attribute of social ecology which Bookchin (1995) called "dialectical naturalism." Dialectical methods can broadly be conceived to have four fundamental principles ${ }^{2}$ which Bookchin embraced but with modifications:

a) Human activities are transient and finite, existing in the medium of time.

b) Human behaviour is composed of contradictions (opposing forces).

c) Incremental changes lead to turning points when one force overcomes its opponent force (quantitative change leads to qualitative change).

d) Change occurs in spiral, not circular form - hence there is an evolution process that comes forth when contradictory perspectives interact with each other.

Bookchin (2005) was quite conscious of differentiating his approach from what he termed Hegel's "empyrean idealism" as well as what he called Marx's "wooden, often scientistic dialectical materialism." His approach embraces science and society as providing feedback loops towards more effective ecologically sustainable governance at a non-hierarchical localized level. Through this process, some mechanisms of governance can be identified and the seemingly contradictory elements of "thinking locally" about its social context but "acting national or globally" on its ecological footprint can find some reconciliation. The spiralling trajectory of dialectical naturalism can thus lead us towards more ecologically viable livelihoods generated from a circular economy in the short-term, and broader community development outcomes in the-long-term. However, such a pathway will require us to navigate in far greater detail specific aspects of circular economic activity in order to make the application of these lofty philosophical principles more palpable for decision-makers in the sector. Elsewhere, I have also argued that such a social ecological approach can help us to grapple with informal economies such as artisanal and small-scale mining or ASM (Ali, 2016) which can present an aberration to neat structured model of a circular economy. Thus gold which ideally should come from recycled cell phones and other electronics in a perfect circular economic model may still need to account for supply chain entry of the metal from artisanal miners. Mining cooperatives may be another important mechanism for implementing a more decentralized approach to ASM in the spirit of subsidiarity. Some of the past challenges of cooperatives, as documented by Levin and Turay (2008) could also be addressed by a social ecology approach. ASM, particularly in the gemstone sector, is a highly individualistic activity and has potential to reduce itself to anarchistic arguments of autonomy from any regulatory mechanism. Fostering the value of cooperation through access to markets has often not been an adequate incentive for developing cooperative systems. Ecological and public-health oriented norms have greater potential for providing an incentive for cooperative development where the miners can see direct benefits of collaboration that could not be realized without some regulatory oversight of mine owners. Some form of standard-setting and regulatory enforcement can be better justified through such means. The dialectical principle of quantitative changes leading to qualitative changes can be embraced in the context of ASM by carefully monitored environmental health and safety education programs, coupled with enforcement against non-compliance. The proverbial "carrot and the stick" can find conceptual harmony through Bookchin's naturalism (Biehl, 2015) and eventually lead to a dialectical "turning point" whereby those engaging in artisanal mining see ecological consciousness as a necessary part of their social system.

${ }^{2}$ These principles can be derived from a variety of texts on dialectics. An excellent framing of the use of this approach in organizations in policy and planning can be found in Mitroff and Emschoff, 1979. 
Ideally we may want for such informal and hazardous activities to become obsolete in a developed country context. However, a pragmatic social ecology approach would attempt to find ways to transition their livelihoods through a series of incremental policy steps. For example, we could start with communal regulation and enforcement mechanisms of artisanal mines coupled with improvement of environmental health and safety conditions of miners. Next, a transitioning process by which the miners could be skilled to undertake micro-smelting operations that can allow for other feed-stocks of metal from recycled source could be brought forth. Hybridity in feedstock could then lead to greater resilience in their livelihoods as the transition to a more circular economic model emerges. Note, however, that in this case as well, interface with the global supply chain would likely be important in most contexts to allow for the supply chain of recycled electronics to enter the micro-smelting economy.

A socio-ecological approach to dialectical thought thus helps us consider some of the aberrations which can arise in complex human systems by noting their inherent contradictions of scale, motives and incentives. It also provides us a way out of the stasis of circularity by positing a "spiral" rather than a two-dimensional circle in the progression of such an economy. Thus innovation and the constant negotiations between competing human interests are accommodated within this paradigm as is the circular economy's imperative of optimizing systems rather than components. The distinction between nested sub-systems and "components" within broader symptoms needs to be defined in terms of social knowledge and hierarchies that could be determined by culture. We could espouse a normative transition of culture towards more sustainable behaviour but such a process must follow the dialectical spiral of naturalism that social ecology presents in an aspiring "circular economy."

\section{The Dilemma of Durability and Development}

A neglected aspect of the circular economy discourse has been an evaluation of how such a paradigm would impact basic human development challenges. There seems to be is a presumption that "win-win" outcomes would emerge from efficient systems in a circular economy that could provide development dividends in the world's poorer nations. Yet some of the dominant premises of a circular economy necessitate reduced consumption and increased durability of material products which has the potential for a major impact on human development in areas that depend on livelihoods from those processes. As a locus of analysis, consumption of myriad products and services, provides an essential link between economic development and environmental impact. Yet a polarized view that considers consumption as only a problem of ecological decadence needs to be avoided.

Optimists in this regard would argue that a transition to a service sector and its concomitant wealth creation would counterbalance the reduced throughput of manufacturing employment and livelihoods for market economies. The transition of livelihoods following automation of major labour-intensive industries during the past century is often alluded to in this vein. However, there are limits to the absorption of employment by the service sector in very high population developing countries such as Nigeria which are aspiring for major development outcomes for their population beyond aggregate indicators of growth.

Still other environmental thinkers have romanticized subsistence economies and disparaged market entry to prevent heightened consumption or dependence on employment for livelihood generation. Within the context of a circular economy, it is also important to note that subsistence has its own challenge towards realizing the goals of sustainability. Although subsistence societies have important survival skills for meeting basic human needs for food and shelter, they are so focused on their immediate family or tribe so as to not contribute more meaningfully to broader societal ambitions. Thus the innovations emanating from subsistence societies are focused on a very narrow sphere of influence (Elias, 2012). The reduction in environmental impact from such insularity which is applauded by many environmentalists (Spence, 2011) is counterweighted by a possible innovation deficit that can occur in such cases (Ali, 2012). 
Population growth, particularly in the context of developing countries, remains an additional imponderable for a more coherent vision for a circular economy. More people can suggest greater innovation potential and an able workforce - often termed "the demographic dividend" -- but also a major drain on resource endowments. The famous IPAT equation (Ecological Impact = Population $X$ Affluence $X$ technology) needs to be revisited here to consider how best to operationalize a circular economy within a development context. The various permutations of this equation have been admirably studied in the pages of this journal before (particularly, Chertow, 2001). Suffice it to say that for our purposes here, the technological variable needs to be better connected to the concept of "planned obsolescence" which is an important feature of consumer product-driven development (Guiltinan, 2009). One effort to incorporate the IPAT analysis within a circular economy has been posited for the development of Shaanxi province in China (Ying and Wen-ping, 2015). However, the technological variable in their analysis is not adequately unpacked to consider the development and innovation dividends of obsolescence (Kurz, 2015). Product design, modularity and finding more ecologically sustainable energy sources would likely be needed to ensure that spiral of development alluded to earlier within a dialectical frame can occur as the circular economy is established.

Transitioning to a circular economy also needs us to consider consumer choice as an important part of the model which can't just be "engineered." Here too social ecology provides us a way forward by focusing on a dialectical process of regulation, education and behavioural change. However, even if regulation is liberally applied to encourage a circular economy or other mechanisms for a more sustainable society, there are still certain fundamental individual liberties that we have now come to accept as beyond the reach of regulation. Regulating birth decisions, for example, would have been the single most potent regulatory mechanism for the ardent neoMalthusian in mitigating resource depletion and environmental harm, but is no longer plausible as a policy choice. Gone are the days when scholars such as Garrett Hardin were proposing "Life Boat Ethics," that advocated apathy towards the poor and the elderly or condoned a demise of populations to sustain "spaceship earth" (Hardin, 1974). Environmentalism has been more universally humanized but it has also led to a conundrum of how best to address our fundamental resource constraints. Even ardent proponents of population control have mellowed their conversations on the matter considering the enormous ethical implications of such rash rhetoric.

Amartya Sen (1970) recognized the challenge of reconciling efficiency and "optimal' societal behavior with liberalism several decades ago in his famous essay "The Impossibility of a Paretian Liberal." There were two articles which challenged some of Sen's arguments ( $\mathrm{Ng}$, 1971; Hillinger and Lapham, 1971) which he responded to with aplomb and rested his case quite definitively (Sen, 1971). Sen was concerned with human propensity for conflict when certain inalienable values collide within a liberal system that may also be trying to achieve "Pareto" optimality. Named after the nineteenth century Italian economist Vilfredo Pareto, this move towards optimality could be theoretically achieved when a movement from one allocation to another can make at least one individual better off without making any other individual worse off. Sen showed that when we define certain unrestricted domains of human behaviour, such as decisions on having children or what we wear or eat, then we cannot aspire towards having an optimal society. Kenneth Arrow arrived at a similar insight with regard to voting behaviour in his famous "impossibility theorem," that suggested that voting systems are not capable of converting the ranked preferences of individuals into a community-wide rankings of societal preferences (Arrow, 1970). Our approach to consumption and the environment must grapple with this fundamental challenge and thus a multifaceted approach with incentive-driven regulations, technological innovation, and literacybased behavioural change is essential. Human ambition or what I refer to as a "treasure impulse" in earlier work (Ali, 2009) has been at the heart of human development should no longer be limited to a base desire to plunder the Earth's resources. However, in our antipathy towards the negative attributes of human ambition and "greed" we should not diminish the impulse to innovate. Rather a more responsible channelling of this impulse can encourage extraction practises of minerals that minimize environmental harm, reduce wastage as well as facilitate green sources of energy 
generation. Innovation is the key that leads to the conceptualization of marketable goods and services and the creation of new livelihood opportunities.

To connect these diffuse ideas I have tried to develop a framework for how to conceptualize the challenge of achieving a circular economy and a sustainable society in a way that integrates livelihoods around human "need" (biophysical necessities) and "greed" (psychosocial attributes that contribute to the quality of life and the ambition to innovate) which is show in Figure 1. As the figure illustrates, the crux of my argument is that if people are informed about the impact of their decisions regarding consumption on the environment as well as livelihoods, the goal of sustainability becomes a broader framework within which both the issues of environmental protection and poverty alleviation are included. However, as portrayed in the diagram, these livelihoods can only be sustained by consumption, whether in the case of biological necessities that satisfy "needs" or social necessities that satisfies "greed". Green arrows indicate positive pathway towards ecological, economic and social sustainability; red arrows define negative pathways for same criteria and yellow arrow defines pathways whose impact can be positive or negative depending on decisions nodes. $\mathrm{S}=$ Subsistence and survivalist demand; $\mathrm{C}=$ direct greed-based consumption (or plunder); $\mathrm{R}=$ Regulatory measures; $\mathrm{I}=$ Innovation Capital; $\mathrm{T}=$ Technologically driven demand; $\mathrm{D}=$ Democratic process. Lower-case notation suggests subsidiary pathway of concept in upper-case. + Indicates pathway with definite positive potential for sustainable development.

Figure 1: Reconciling Human "Need" and "Greed" in a Circular Economy (labels described in text)

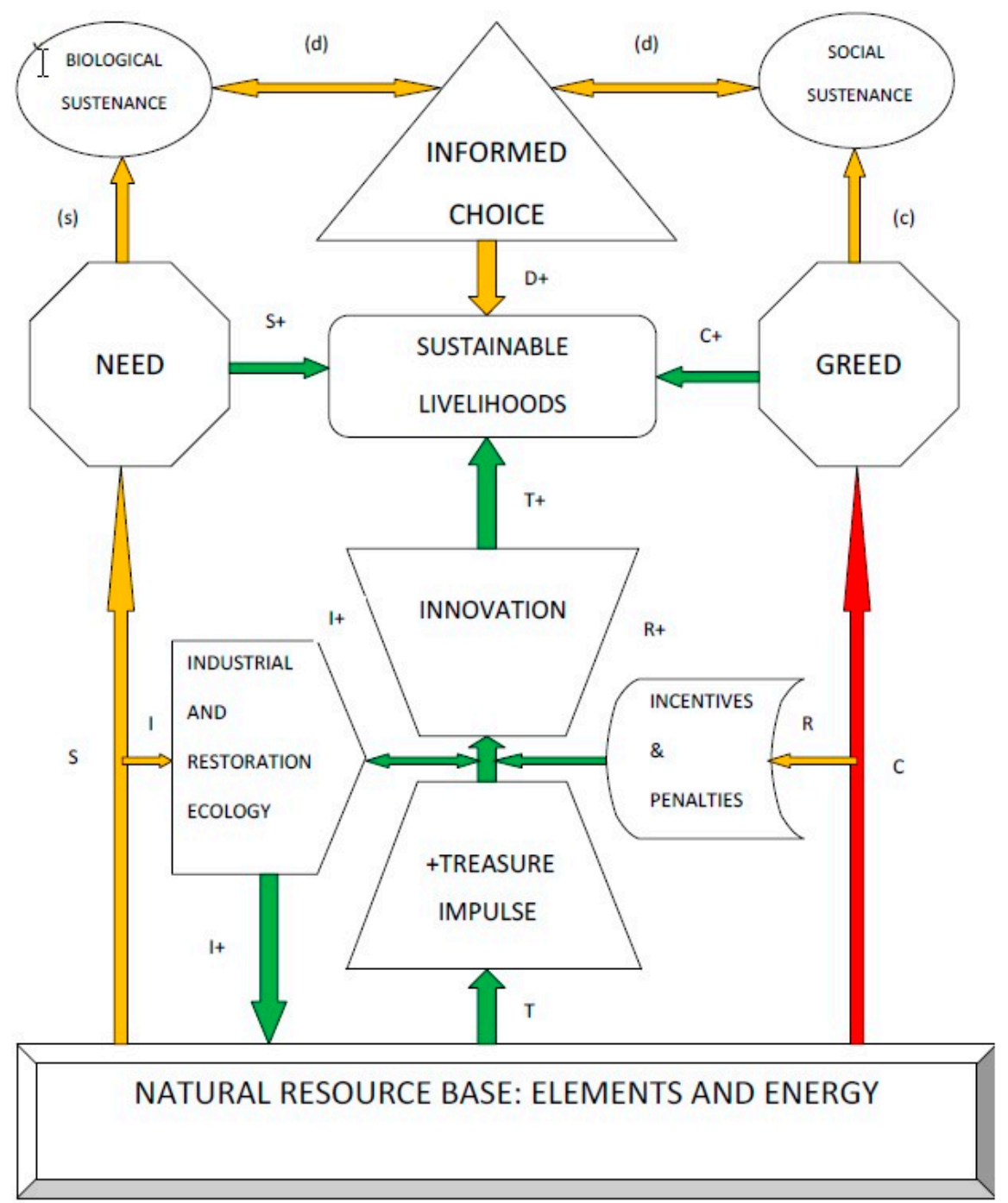


Incentive-driven development paths necessitate some measure of consumerism around luxury goods in developed countries. No doubt the outcome of such a path will be suboptimal from the perspective of purely environmental conservation. In a society that values some norms of human choice regarding well-being we will always contend with some win-lose propositions. We can educate and regulate but must always be cautious about totalitarianism for that may stifle our ultimate salvation out of the environmental crisis - the capacity to innovate.

Innovation to improve efficiency can be an important feature of finding win-win outcomes for a circular economy. However, the well-known discourse on "Jevons Paradox" (named after the nineteenth century coal economist who proposed it) suggests that efficiency and consumption need to be better understood. If there is latent demand, for consumer goods, efficiency within a circular economic system could still increase overall consumption. In other words since efficiency is likely to reduce cost, there will be greater demand for the same good and a "rebound" in consumption will occur as a result. This observation is often presented by environmentalists as an antidote to technological optimism with regard to energy and material efficiency. The same argument can also be made for dematerialization - as lesser material is used for manufacturing a product, more of the raw material will be available for other goods spurring latent demand in other products that could use that material. Within a circular economy model that keeps in view dialectical approaches, the latent demand can be more easily identified since embracing such "contradictions" is one of the seminal principles of dialectical naturalism. While the paradox may well hold in the case of materials and energy usage areas with growing demand, it is less likely to be valid in mature markets. For example, in a developing economy energy efficiency and reduced cost may lead people to buy more products to use more energy. However, in a market with a fairly saturated consumption profile (not many more things to add to material and energy demand), efficiency and dematerialization are very valuable. We can thus be cautiously optimistic about the prospect of channelizing our treasure impulse towards seeking efficient material usage (Ausubel and Waggoner, 2008).

Tying together material cycles across spatial dimensions of resource availability and waste management schemes can be achieved through a social ecological interpretation of a circular economy. However, we are still left to consider the temporal dimension of resource extraction. Planned conservation and efficient cycling of wastes may extend our time horizon for depletion and perhaps give technology a greater opportunity to find alternatives. Ultimately, our only salvation in grappling with the durability and development dilemma will be in finding energy sources which can be developed most effectively with existing materials available within a circular economy. One of the key tenets of dialectical naturalism is that incremental change leads to "turning points." The long-term viability of a circular economy will ultimately depend on a turning point around efficient and effective energy availability. Such a turning point would allow for many of the other contradictions and imponderable elements of reconciling material flows and development challenges would also be addressed. However, there would need to be a global effort to ensure resources are most effectively channelled in this regard through improved governance systems for resource flows.

\section{Conclusion: Towards a Model for Governing a Circular Economy}

Critics of a circular economy summarily argue that structured management of material flows leads to centralized planning which failed in history starting with the Greeks, the Romans, and more recently with the Soviet Union. It is important not to confuse thought and process at this juncture. The vision of a circular economy, though stressing the intrinsic interrelationships between various biotic and abiotic processes does not necessarily imply that we centralize efforts to deal with all material problems. Indeed, the social ecology lens for viewing a circular economy has its origins in devolved coordination. We need to be far more discerning than to simply propose a single set of solutions that are hierarchically determined. However, global coordination of solutions and a constant effort to harness planetary synergies that transcend the borders of nation 
states is essential, particularly when there are international coordinated efforts on development goals targets that could possibly conflict with the most expedient paths towards a circular economy.

Perhaps, the approach recently posited by Capra and Mattei (2015) in their book the Ecology of Law can provide better guidance in this regard. In their view in order to have functional economies involving natural resource extraction, we need to transform "legal institutions from being machines of extraction, rooted in the mechanistic functioning of private property and state authority, into institutions based on ecological communities" (Capra and Mattei, 2015, p. 5). Governance and regulatory enforcement through such "ecological communities" that have appropriate education on natural constraints of extraction is likely to be the best way to manage a circular economy.

We could also invoke Agrawal's notion of "environmentality" (Agrawal, 2005) that builds on Foucault's seminal work on knowledge and power (Foucault, 2010) in governance beyond conventional political institutions (governmentality). The role of governments thus becomes one of enabling knowledge acquisition in communities. Governments can also provide a forum to negotiate the contradictions in development objectives which the theory of dialectical naturalism suggests they will inevitably encounter. Beyond a theoretical lens, implementing a social ecological vision of a circular economy would require international environmental diplomacy. We cannot escape the need for some broader international agreements on resource flows that encourage environmentally and socially responsible recycling of waste and more ecologically and economically efficient energy transfers across borders. No doubt there will need to be some reform of international environmental diplomacy (Susskind and Ali, 2014) to facilitate such processes. However, such reforms are plausible and possible as greater awareness and mainstreaming of a circular economy slowly takes root in international affairs around sustainability.

\section{References}

Agrawal, A., 2005. Environmentality: Technologies of Government and the Making of Subjects. Durham NC: Duke University Press.

Ali, Saleem H., 2016. The Social Ecology of Artisanal Mining: Between Romanticism and Anathema " in LahiriDutt, Kuntala ed. Between the Pick and the Plough: Informal Mining in the Contemporary World. Canberra, Australia: Australian National University Press (open-source e-book), Forthcoming

Ali, Saleem H. 2009. Treasures of the Earth: Need, Greed and a Sustainable Future. New Haven CT: Yale University Press.

Ali, Saleem H. 2010. “Cultivating Chaos.” Science Vol. 329, Issue 5990, pp. 392.

Ausubel, Jesse and Paul E. Waggoner. 2008. "Dematerialization: variety, caution and persistence." Proceedings of the National Academy of Sciences,_Vol. 105(35): 12774-12779.

Arrow, Kenneth J. Social Choice and Individual Values, Second edition, 2nd ed. New Haven: Yale University Press.

Bekker, I., 2015. On Pope Francis' Laudato si' and the ideas of Murray Bookchin. Paper presented at the Transational Institute for Social Ecology, Patras, Greece, August.

Biehl, J., 2015. Ecology or Catastrophe: The Life of Murray Bookchin. 1 edition. Oxford University Press.

Bookchin, M., 1995a. Social Anarchism or Lifestyle Anarchism: An Unbridgeable Chasm. Edinburgh, Scotland ; San Francisco, CA: AK Press.

Bookchin,. 1995b. Philosophy of Social Ecology. 2 edition. Montréal : New York: Black Rose Books.

Brincat, S. and D, Gerber., 2015. "The Necessity of Dialectical Naturalism: Marcuse, Bookchin, and Dialectics in the Midst of Ecological Crises." Antipode 47 (4): 871-93. Bryceson, D. F. and J. B. Jønsson., 2010. “Gold Digging Careers in Rural East Africa: Small-Scale Miners' Livelihood Choices." World Development 38 (3): 379-92.

Capra, F. and U. Mattei., 2015. The Ecology of Law: Toward a Legal System in Tune with Nature and Community. 1 edition. Oakland, CA: Berrett-Koehler Publishers.

Chertow, Marion. 2001, "The IPAT Equation and its Variants: Changing Views of Technology and Environmental Impact," Journal of Industrial Ecology, 4(4): 13-29.

Daly, Herman. 1991. Steady State Economics (Second Edition). Washington DC: Island Press.

Dyball, R. and B. Newell., 2014. Understanding Human Ecology: A Systems Approach to Sustainability. London UK: Routledge. 
Elias, Scott ed. 2012. The Origins of Human Innovation and Creativity. Dordrecht, The Netherlands: Elsevier.

Foucault, Michael. 2010. The Government of Self and Others: Lectures at the Collège de France 1982-1983, edited by Arnold I. Davidson, translated by Graham Burchell. New York: Palgrave Macmillan, 2010.

Gabriela-Cornelia, P., Iudith, I., Alexandru, B., 2015. New Theoretical and Practical Approaches of Implementing the Circular Economy for the Preservation of Natural Resources. Procedia Economics and Finance, 2nd International Conference "Economic Scientific Research - Theoretical, Empirical and Practical Approaches", ESPERA 2014, 13-14 November 2014, Bucharest, Romania 22, 124-130.

George, D.A.R., Lin, B.C., Chen, Y., 2015. A circular economy model of economic growth. Environmental Modelling \& Software 73, 60-63.

Gregson, Nicky, Mike Crang, Sara Fuller and Helen Holmes 2015. "Interrogating the circular economy: the moral economy of resource recovery in the EU." Economy and Society - Volume 44, Issue 2,2: 218-243.

Hillinger, C. and V. Lapham, "The Impossibility of a Paretian Liberal: Comment by Two Who Are Unreconstructed", The Journal of Political Economy 79, no. 6 (December 1971): 1403-1405.

Hardin, Garrett 1974. "Life-boat ethics: The Case Against Helping the Poor", Psychology Today (September, 1974).

Kurz, Rudy. 2015. “Quality, Obsolescence and Unsustainable Innovation.” Ekonomski Vjesnik XXVII:2, pp. 511522.

Ng, Y. K. 1971. "The Possibility of a Paretian Liberal: Impossibility Theorems and Cardinal Utility", The Journal of Political Economy, Vol. 79, No. 6 (Nov-Dec 1971): 1397-1402.

Sauvé, S., Bernard, S., Sloan, P., n.d. Environmental sciences, sustainable development and circular economy: Alternative concepts for trans-disciplinary research. Environmental Development.

Sen, Amartya. 1970. "The Impossibility of a Paretian Liberal", The Journal of Political Economy, Vol. 78, No. 1 (Jan-Feb 1970): 152-157.

Spence, Spencer (2010). Pandora's Seed: The Unforseen Cost of Civilization. New York: Random House.

Susskind, Lawrence and Saleem H. Ali. 2014. Environmental Diplomacy: Negotiating more Effecting International Agreements. New York and Oxford: Oxford University Press.

World Economic Forum. 2014. Towards the Circular Economy. Geneva: WEF Publications, Available online at: http://reports.weforum.org/toward-the-circular-economy-accelerating-the-scale-up-across-globalsupply-chains/

Ying, F., Wen-ping, Z., 2015. “Circular Economy Development Phase Research Based on the Ipat Equation: The Case of Shaanxi." Economic Horizons 17:1, 33-43.

(C) 2016 by the authors; licensee Preprints, Basel, Switzerland. This article is an open access article distributed under the terms and conditions of the Creative Commons by Attribution (CC-BY) license (http://creativecommons.org/licenses/by/4.0/). 